\begin{tabular}{|c|c|c|}
\hline $\begin{array}{l}\text { PKS } \\
\text { PUBLIC } \\
\text { RNIONLEDGE } \\
\text { PROJECT }\end{array}$ & $\begin{array}{l}\text { REVISTA DE GEOGRAFIA } \\
\text { (RECIFE) } \\
\text { http://www.revistautfe.brfrevistageografia }\end{array}$ & 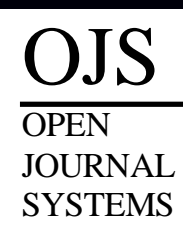 \\
\hline
\end{tabular}

\title{
ESTUDO GEOMORFOLOGICO EM CAVERNAS DE ARENITO DA AMAZÔNIA PARAENSE
}

\author{
${ }^{1}$ Luciana Martins Freire; ${ }^{2}$ Joselito Santiago de Lima; ${ }^{3}$ Cesar Ulisses Vieira \\ Veríssimo; ${ }^{4}$ Edson Vicente da Silva
}

${ }^{1}$ Professora Adjunta do Campus Universitário de Ananindeua da UFPA. Email: lucianamf@ufpa.br
${ }^{2}$ Professor do Campus Óbidos do IFPA. Email: joselito.lima@ifpa.edu.br
${ }^{3}$ Professor Titular do Departamento de Geologia da UFC. Email: verissimo@ufc.br
${ }^{4}$ Professor Titular do Departamento de Geografiada UFC Email: cacauceara@gmail.com

Artigo recebido em 11/12/2017 e aceito em 09/03/2018

\begin{abstract}
RESUMO
Na região Amazônica, rica em feições geomorfológicas resultantes da interação sistêmica de elementos da natureza, ocorrem muitas cavernas em arenitos. Como exemplo, tem-se a Província Espeleológica AltamiraItaituba (estado do Pará), situada na faixa de contato dos domínios geológicos da bacia sedimentar do Amazonas e do embasamento cristalino do complexo Xingu. Nesse sentido, o estudo proposto, com base na análise geossistêmica da paisagem, apresenta uma ampliação dos estudos sobre carste em rochas não carbonáticas, contribuindo para os estudos espeleológicos no Brasil. A estrutura geológica das cavernas da Província apresenta-se notadamente em arenitos friáveis da For ᄀmação Maecuru, pertencente ao Grupo Urupadi. Os processos que envolvem a formação das cavernas estão associados principalmente à ação mecânica da água (erosão hídrica), embora a ação química da água apresente papel fundamental na dissolução intergranular.
\end{abstract}

Palavras-chave: Carste não carbonático; Espeleologia; Amazônia.

\section{GEOMORPHOLOGICAL STUDY IN CAVES OF THE SANDSTONE OF THE AMAZON PARAENSE}

\begin{abstract}
In the Amazon region, which is rich in geomorphological features resulting from systemic interaction of nature elements stand out caves in sandstones. For example, there is the Speleological Province Altamira-Itaituba (Pará State), located in the geological domains of the sedimentary basin of the Amazon the contact zone of with the crystalline basement of the Xingu complex. In this sense, the proposed study, based on the geosystemic analysis of the landscape, presents an amplification of the studies on karst in non-carbonate rocks, contributing to speleological studies in Brazil. The geological structure of the caves of the Province presents notably in friable sandstone of Maecuru Formation belonging to Urupadi Group. Processes involving the formation of the caves are mainly associated with the mechanical action of water (hydric erosion), although water chemical action present fundamental role on intergranular dissolution.
\end{abstract}

Key-words: Non-carbonate karst; Speleology; Amazon.

\section{INTRODUÇÃO}

$\mathrm{Na}$ região Amazônica é identificada a presença de relevo cárstico de rochas siliciclásticas. Algumas dessas paisagens de exceção encontram-se inseridas no contexto geológico da bacia sedimentar do Amazonas e fazem parte de um conjunto paisagístico denominado Província Espeleológica, composta por rochas susceptíveis aos processos 
cársticos. Nesse contexto geológico-geomorfológico, apresenta-se a Província Espeleológica Altamira-Itaituba (Figura 01), localizada no estado do Pará, que se destaca por ser um conjunto de cavidades naturais subterrâneas com diferentes feições endogenéticas, em sua maioria formada pelo processo de arenitização (desgaste das rochas por água meteóricas).

Figura 1- Mapa de Localização das cavernas da Província Espeleológica Altamira-Itaituba (PA)

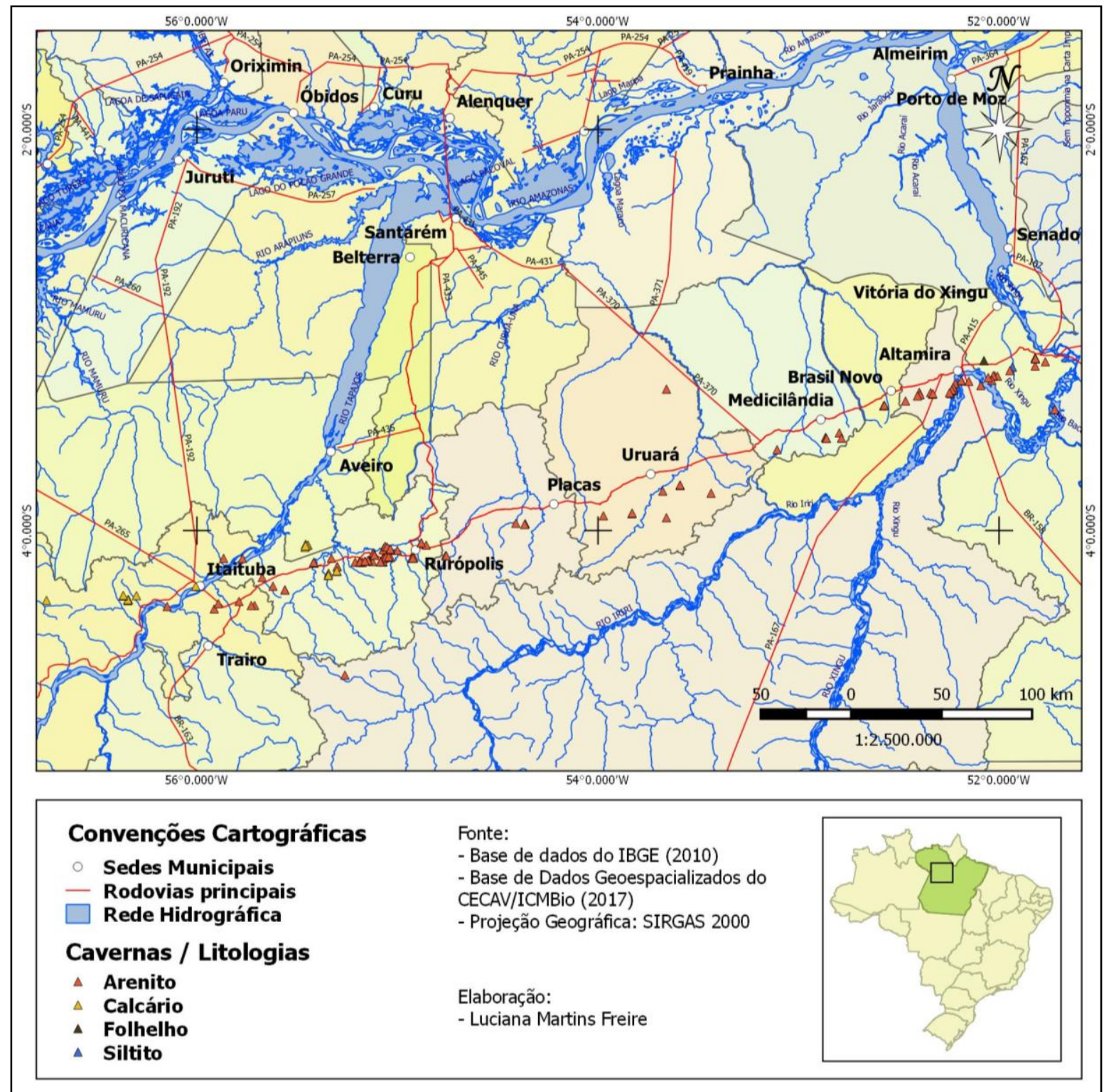

Em se tratando de paisagem cárstica, os setores da Província apresentam um ambiente cujas feições não foram desenvolvidas no contexto de rochas carbonáticas, apresentando uma estrutura predominantemente de rochas em arenito. Importante salientar que a Geomorfologia Cárstica não se refere apenas ao carste desenvolvimento em rochas carbonáticas. São reveladas cavernas bem desenvolvidas em rochas tais como arenitos, quartzitos, gnaisses, 
micaxistos, basaltos, formações ferruginosas, rochas vulcânicas alcalinas, entre outras, indicando uma extensão do uso do termo aplicado a outras rochas, em que os processos espeleogenéticos não estão, seguramente, relacionados com dissolução (como ocorre nas rochas carbonáticas). Em rochas siliciclásticas predominam processos mecânicos. Enquanto nas rochas carbonáticas a porosidade primária não é recorrente, predominando a secundária (aquífero em meio fissural), nas rochas siliciclásticas a porosidade primária é regra (aquífero em meio poroso).

A ocorrência de camadas de arenito friável, o fraturamento da estrutura geológica, de origem tectônica, associado às variações isostáticas, deram início ao processo que gerariam as cavernas na Província Espeleológica Altamira-Itaituba. A ação mecânica da água (erosão hídrica e arenitização), verificados pela subida do nível do lençol freático, submeteu o arenito a condições freáticas, apresentando-se então um dos principais fatores de esculturação das cavidades.

Sabe-se que as condições climáticas das regiões tropicais e equatoriais apresentam precipitações anuais com médias pluviométricas de 1000 a $4000 \mathrm{~mm}$, agindo mecanicamente de maneira mais intensa nos processos de desenvolvimento de cavernas. Contudo, as condições de altas temperaturas e umidade, bem como a presença de matéria orgânica abundante, fazem com que o ambiente produza mais $\mathrm{CO} 2$, resultando na atividade química nas rochas, ao passo que a ação química da água tenha papel fundamental na dissolução intergranular.

Este artigo científico apresenta uma contribuição sobre a paisagem endocárstica em rochas areníticas, bastante comum na Amazônia. Considerando que a Espeleologia é uma atividade de múltiplo sentido (científico, esportivo, turístico e sociocultural), o objetivo desta pesquisa é contribuir para o aprofundamento e disseminação de conhecimentos particulares do carste em rochas não carbonáticas. Nesse sentido, tem-se um estudo de caso dos arenitos da formação Maecuru, por meio de estudos realizados na paisagem da Província Espeleológica Altamira-Itaituba (PA).

\section{MATERIAL E MÉTODOS}

\section{Área de estudo}

As cavernas da Província Espeleológica Altamita-Itaituba ocorrem nos municípios paraenses de Altamira, Anapú, Aveiro, Brasil Novo, Itaituba, Medicilândia, Placas, Rurópolis, Uruará e Vitória do Xingu. As cavernas estão localizadas ao longo da borda sul da bacia 
sedimentar do Amazonas, coincidindo com as proximidades do rio Xingu, em seu baixo curso, e da rodovia Transamazônica (BR-230). Contudo, nesta pesquisa, são apresentadas como exemplos as cavidades naturais subterrâneas desenvolvidas em arenitos da porção nordeste da província, como destacadas na figura 2 , tendo como principais cavernas as da, Pedra da Cachoeira, Planaltina e do Limoeiro, respectivamente nos municípios de Altamira, Brasil Novo e Medicilândia.

Figura 2 - Mapa de representação das cavernas areníticas estudadas.

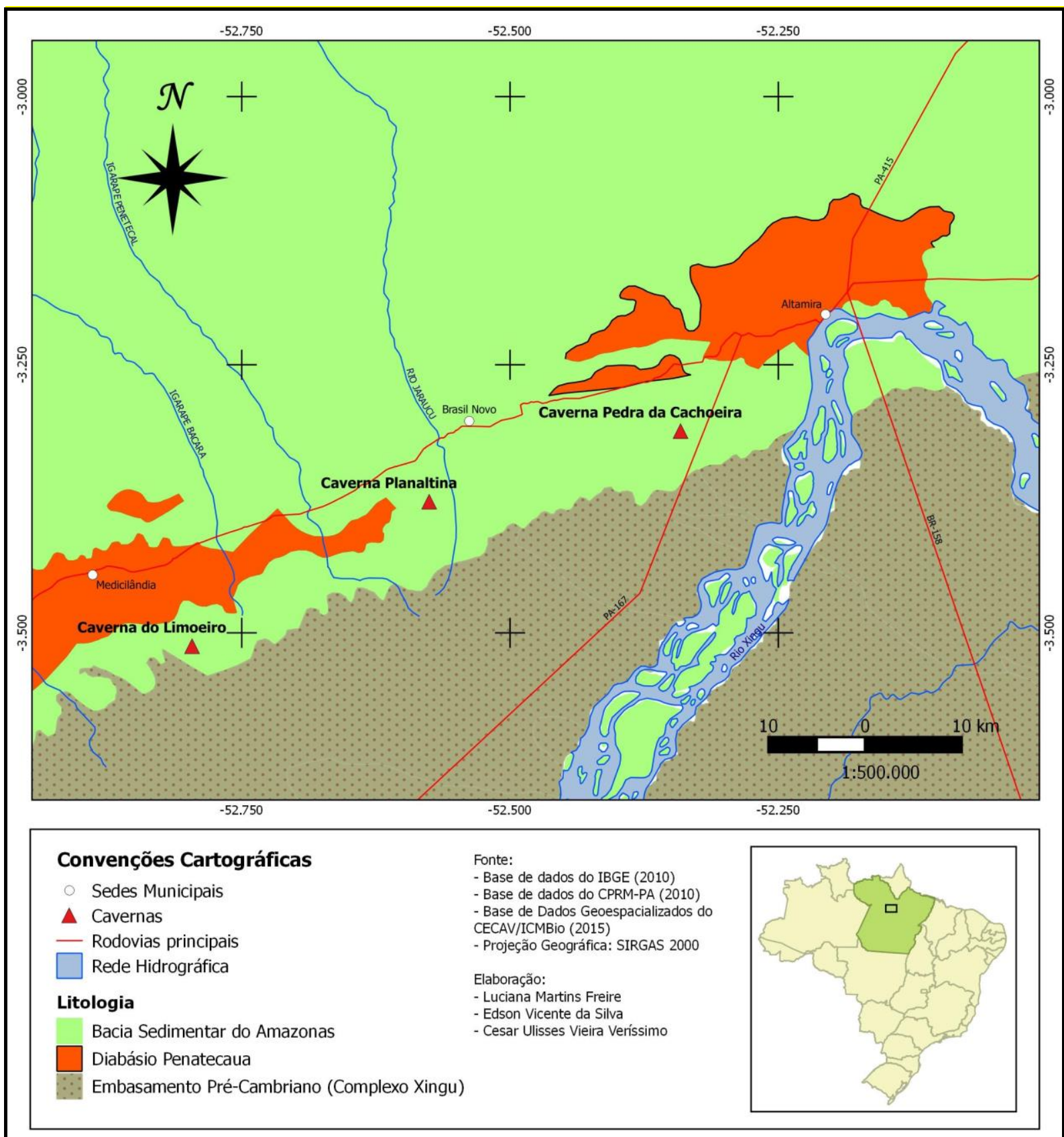




\section{Metodologia}

A análise geossistêmica é definida a metodologia da pesquisa, em busca do entendimento da constituição do ambiente espeleológico, envolvendo os aspectos da dinâmica geológica e geomorfológica da estruturação da paisagem cárstica, oferecendo assim as bases para um conhecimento sobre o processo de formação das cavernas.

O estudo sistêmico é realizado mediante análise e investigação das partes componentes de um todo, que é o conjunto de elementos relacionados entre si e com certo grau de organização os quais atingiram determinado objetivo ou finalidade. Sotchava (1977) afirma que a teoria geossistêmica demonstra que na análise da paisagem devem-se estudar as conexões entre os componentes da natureza, e não eles separados do todo. O conceito de paisagem é inserido ao estudo de geossistemas pelo fato de ser apontado como o efeito visual ou uma representação daquilo que é percebido, por meio da conjunção de objetos visíveis pelo sujeito vinculados às suas necessidades e perspectivas de uso (BERTRAND, 2004).

O levantamento de bibliografias relacionadas a área de estudo, com textos e documentos que subsidiaram a identificação das paisagens espeleológias alocadas no domínio da Amazônia fez parte do primeiro momento da pesquisa. Assim, realizou-se uma pesquisa sobre a geologia e geomorfologia da bacia sedimentar do Amazonas, identificando os processos naturais de formação de províncias espeleológicas nesse ambiente. Citam-se: Projeto RADAMBRASIL - DNPM (1974); Vasques e Rosa-Costa (2008); e Ministério de Minas e Energia - MME (2009). As informações referentes à área da Província Espeleológica Altamira-Itaituba foram adquiridas com base no exame e análise de material bibliográfico e cartográfico produzido por instituições oficiais, tais como: Centro Nacional de Estudo, Proteção e Manejo de Cavernas / Instituto Chico Mendes (CECAV/ICMBio); Sociedade Brasileira de Espeleologia (SBE); Companhia de Pesquisa de Recursos Minerais (CPRM); Projeto RADAM Brasil, produzido pelo DNPM; arquivo técnico-científico do Grupo Espeleológico Paraense - GEP, artigos científicos (Pinheiro et al., 2015) e documentos exigidos para a autorização da implantação do Aproveitamento Hidrelétrico (AHE) de Belo Monte, tais como a Avaliação Ambiental Integrada (AAI) dos Aproveitamentos Hidrelétricos da Bacia Hidrográfica do Rio Xingu (BRASIL/MME, 2009) e Estudo de Impactos Ambiental (EIA) do AHE Belo Monte (ELETROBRÁS, 2009).

Posteriormente, foram realizados os trabalhos de campo, obedecendo-se às condições climáticas favoráveis (principalmente nos períodos de estiagem), abrangendo um território no qual estão inseridos os municípios paraenses das três principais cavernas da província: 
Altamira (Caverna Pedra da Cachoeira), Brasil Novo (Caverna Planaltina) e Medicilândia (Caverna do Limoeiro). O acompanhamento ocorreu com auxílio de cartas e mapas em escalas 1:125.000 (ELETROBRÁS) e 1:1.000.000 (CPRM) já produzidos sobre a região estudada. Além da comprovação dos dados bibliográficos, foram descritos detalhamentos das características espeleométricas (medidas dos condutos e salões, tipos de espeleotemas, dentre outras) e das condições hidrogeológicas da região em que estão inseridas as cavernas.

\section{RESULTADOS E DISCUSSÕES}

A Província Espeleológica Altamira-Itaituba ocorre próximo ao ambiente de contato entre a Bacia Sedimentar do Amazonas (em sua borda sul) e o Embasamento Pré-Cambriano Complexo Cristalino do Xingu. Concentra-se em uma área ao sul da Bacia Sedimentar do Amazonas, na região entre os rios Xingu e Tapajós, delimitada numa estreita faixa com aproximadamente duzentos quilômetros de eixo maior e vinte e cinco quilômetros de eixo menor, com feições dispostas em faixas subparalelas com direção geral ENE-WSW, com o rio Xingu constituindo o limite leste (ELETROBRÁS, 2009; PINHEIRO et al., 2015). Por esse motivo, as estruturas escarpadas da borda de cuesta, com inclinações entre três e cinco graus, abrigam boa parte das cavidades naturais subterrâneas da Província.

A grande Sinéclise Amazônica resultou de prolongados processos de sedimentação iniciados no Paleozóico, da qual a Bacia do Amazonas estende-se por uma área de aproximadamente quinhentos mil quilômetros quadrados. Esta bacia sedimentar foi formada por sucessivas transgressões marinhas epicontinentais sobre o Cráton Amazônico e exibe discordâncias erosivas e hiatos de sedimentação, entre o Neo-ordoviciano e o Neoperminiano, intercalados por soerguimentos vinculados às orogenias relacionadas a abertura do Atlântico Equatorial e à separação das placas Africana, Norte-Americana e Sul-Americana durante o Cretáceo e o Paleoceno (VASQUES; ROSA-COSTA, 2008). Na sequência, passaram por processos de estruturação, morfogêneses e sedimentação até hoje atuante, relacionadas à atividade neotectônica do tipo transcorrente. "Dois pulsos de movimentação, atribuídos aos intervalos Mioceno-Plioceno e Pleistoceno superior-Holoceno, estão representados por deslocamentos, sedimentação, morfogênese e controle de drenagem" (SUGUIO, 2010, p.258).

O relevo da região da Província Espeleológica Altamira-Itaituba caracteriza- se por vales encaixados em baixas altitudes e colinas e topos de platôs em cotas em torno de $120 \mathrm{~m}$, amplitude de cotas altimétricas que variam entre $50 \mathrm{~m}$ e $100-180 \mathrm{~m}$, com predominância de morros aplainados e ocorrências eventuais de cristas suaves e recobertos por capa laterítica. 
Essa capa é resultado do arenito endurecido por silicificação e/ou ferruginização de origem intempérica, de idade terciária, desenvolvendo assim platôs mais resistentes ao desgaste físico-erosivo (erosão diferencial), aprofundando vales e gerando encostas íngremes nos fronts das cuestas.

As frentes de cuestas são descontínuas, com fronts voltados para sul, onde as cavernas estão alocadas em suas bases, logo acima dos leques de colúvios (depósitos de talus), e em vales encaixados nas incisões dos platôs (PINHEIRO et al., 2015). Localmente na área de estudo, além do rio Xingu há também ocorrência de alguns afluentes (chamados regionalmente de igarapés) que se originam em nascentes dispostas ao longo dos vales e surgências de águas no interior das cavernas. A drenagem subterrânea (horizontal e vertical) é o principal responsável pelo padrão erosivo das paredes laterais. Em algumas cavernas da região, é possível perceber marcas de deslocamentos da drenagem em galerias atualmente secas.

Especificamente, a estrutura geológica das cavernas da Província apresenta-se notadamente em arenitos da Formação Maecuru, pertencente ao Grupo Urupadi, de ampla ocorrência na Bacia do Amazonas e que registra um novo ciclo sedimentar. O Grupo Urupadi, com posicionamento litoestratigráfico no Eo-Devoniano, entre 416 milhões e 397 milhões e 500 mil de anos atrás, está sobreposto ao Grupo Trombetas, do Siluriano (VASQUES; ROSA-COSTA, 2008).

Na carta litoestratigráfica da Bacia do Amazonas (Figura 03) é possível visualizar as sequências sedimentares da região estudada, bem como a evolução tectônica e o ambiente deposicional envolvidos na formação.

As cavidades em arenito da Província Espeleológica Altamira-Itaituba (PA) são formadas pelo processo de arenitização, que representa o ataque geoquímico resultante da corrosão química das rochas por águas meteóricas ácidas, em que nesse estágio parte do cimento silicoso da rocha é dissolvido, deixando assim a rocha friável (PINHEIRO et al., 2015; FREIRE et al., 2015). Tal processo é iniciado no Quaternário, marcado pelas variações climáticas estabelecidas nesse período, levando assim ao entalhe dos padrões de escoamento que foram desenvolvendo-se ao longo do tempo.

De acordo com ELETROBRÁS (2009), a dissolução do quartzo durante o processo de arenitização da rocha pode tomar dois caminhos: "se a taxa de dissolução da sílica é baixa, a dissolução fica restrita às bordas dos grãos ou cristais, ou seja, em seus contatos; se a taxa 
de dissolução é muito alta, sem aumento da solubilidade, a topografia pode ser afetada por ação desse processo e desenvolver morfologia característica de terrenos cársticos" (p. 73).

Figura 3 - Carta litoestratigráfica da Bacia do Amazonas.

Fonte: VASQUES e ROSA-COSTA, 2008, p. 202.

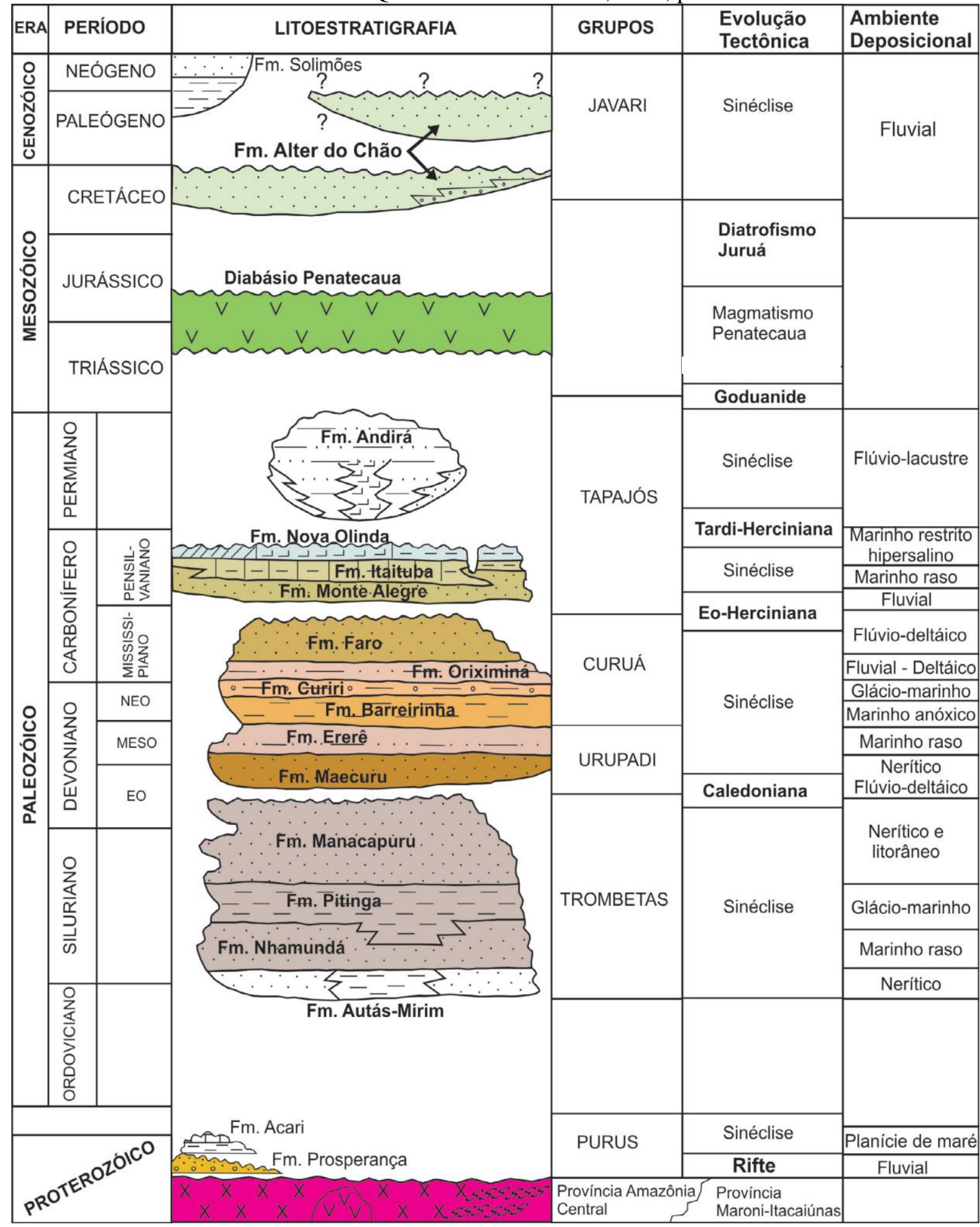


Pinheiro, Maurity e Pereira (2015) sugeriram episódios sequenciais para explicar a ocorrência de cavernas na Província Espeleológica Altamira-Itaituba - PA (Figura 04):

Figura 4 - Explicação esquemática dos estágios de desenvolvimento de cavernas areníticas na Província Espeleológica Altamira-Itaituba. Fonte: Adaptado de Pinheiro, Maurity e Pereira (2015, p.

14)

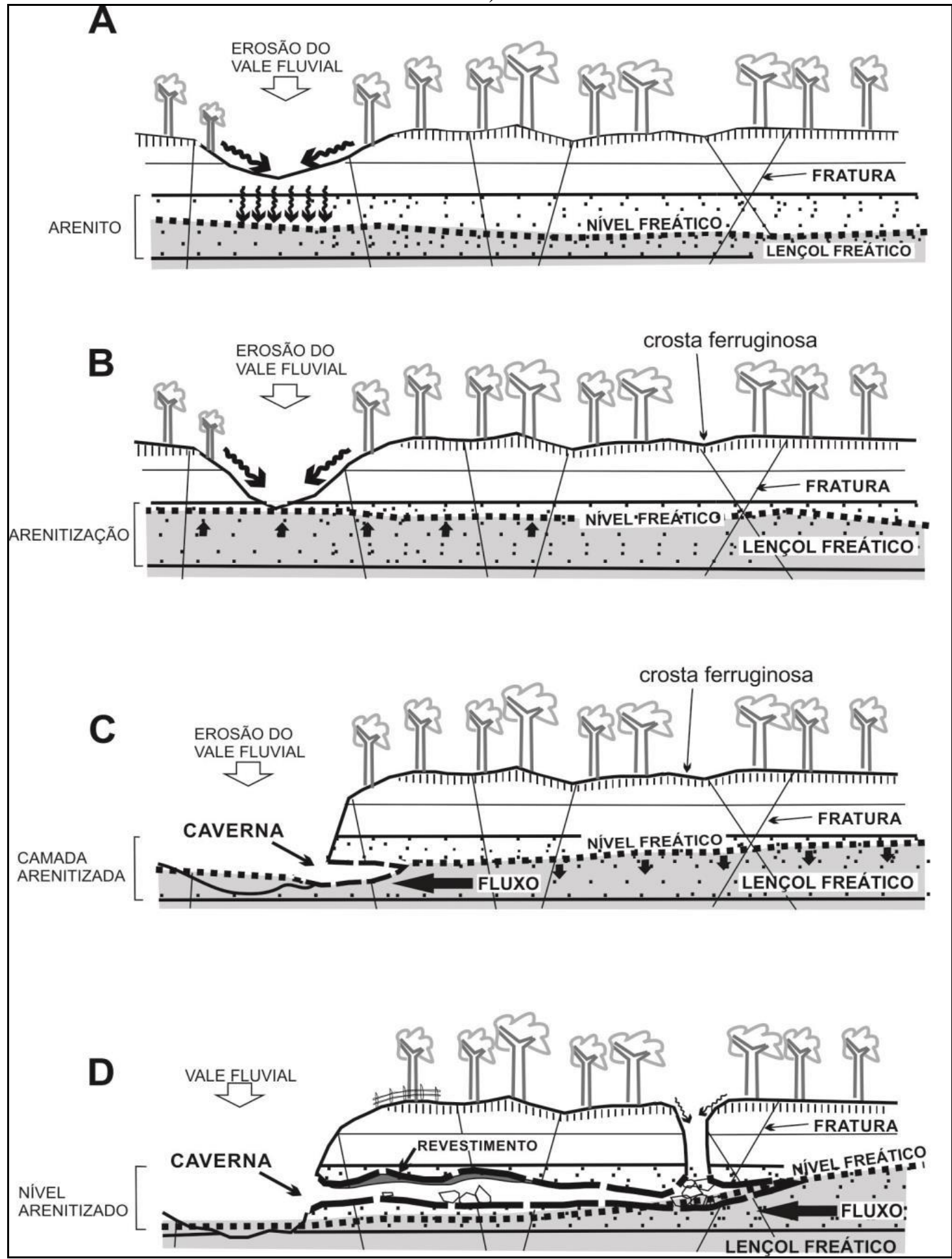


A. Fraturamento da estrutura geológica, de origem tectônica, associado às variações isostáticas, resultante da esculturação do relevo pela erosão (Figura 05);

B. Processos erosivos e intempéricos verificados pela subida do nível do lençol freático, submetendo o arenito a condições freáticas, configurando-se assim o início do processo de arenitização;

C. Oscilações do nível do lençol freático;

D. Erosão da rocha friável por fluxo dirigido pelas fraturas, levando a ampliação e exposição dos condutos e galerias em ambiente vadoso por meio da remoção de partículas da rocha induzida pelo fluxo hidráulico (piping), ação gravitacional e escavação fluvial (Figura 06).

Figura 5 - Fraturamento na Caverna da Planaltina (Brasil Novo-PA) condicionando a esculturação cárstica por meio dos processos erosivos.

Fotos: Luciana Freire, 2015.

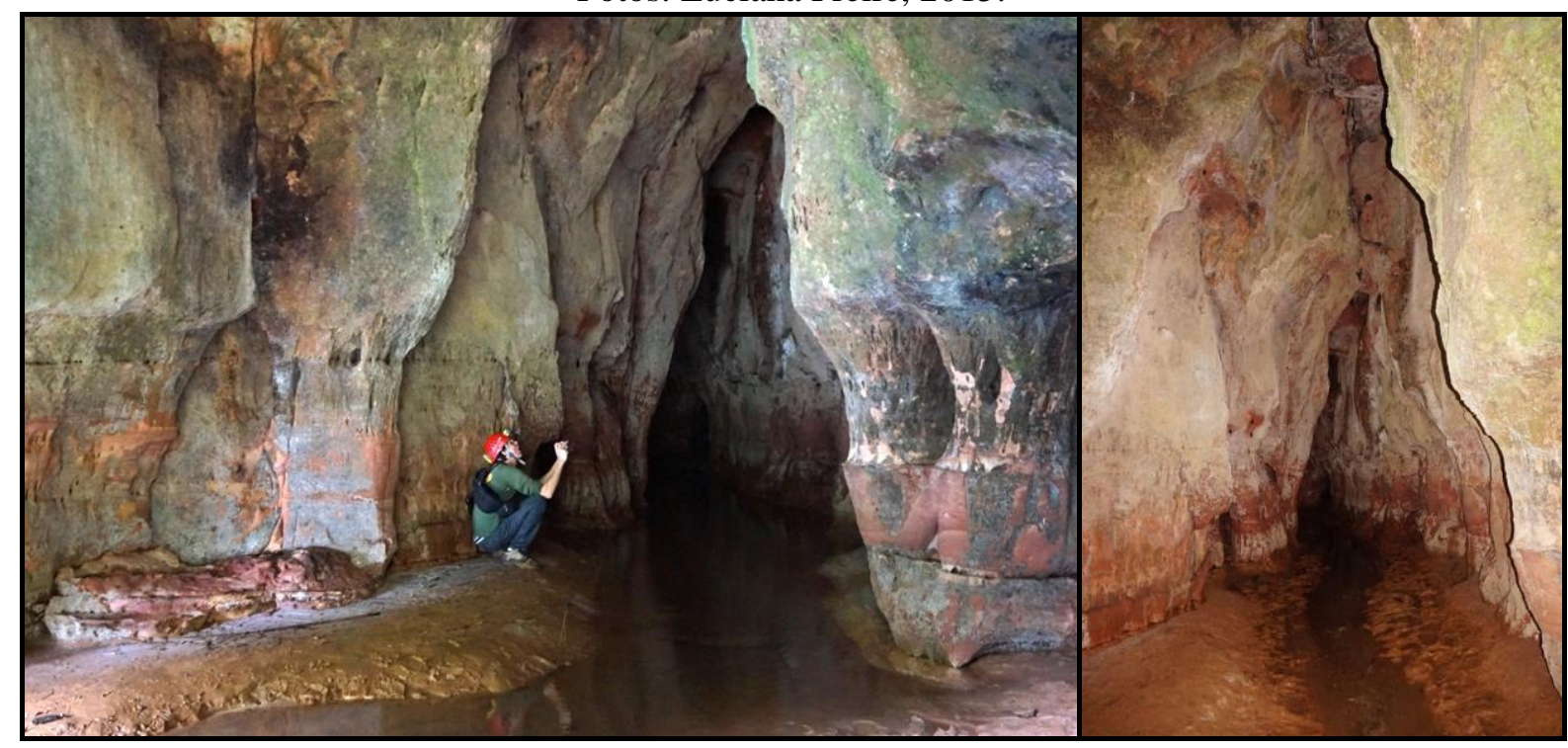

Os estágios de desenvolvimento das cavernas e a distribuição das suas formas revelam um verdadeiro sistema organizado de acordo com a funcionalidade dos elementos envolvidos, o que caracteriza o sistema cárstico. Trata-se de um sistema aberto, em que há o ingresso, o transporte e a saída de água, além de outros elementos minerais e orgânicos carreados junto. 
Figura 6 - Ampliação e exposição dos condutos e galerias evidenciados pela oscilação do nível do lençol freático (caixa de ovos no teto), processos erosivos (escavamento do relevo pelo fluxo d'agua), desagregação mecânica dos grãos (paredes) e intemperismo químico (parte escurecida do teto) na

Caverna Pedra da Cachoeira (Altamira-PA). Foto: Luciana Freire, 2015.

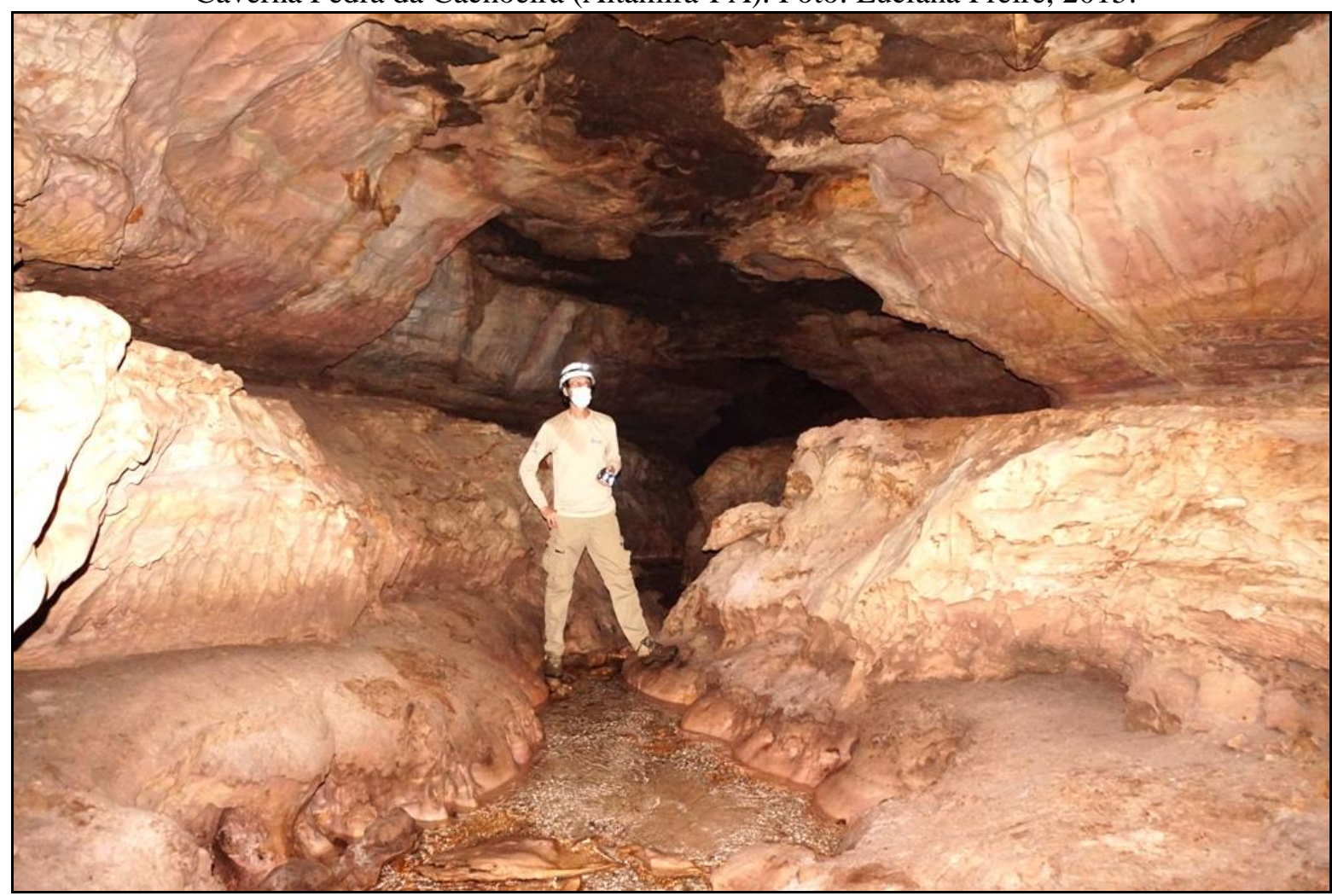

Sendo assim, a paisagem espeleológica surge como resultado de processos sequenciais organizados, que revelam uma distribuição espacial cárstica reconhecida, permitindo assim o entendimento do funcionamento do sistema. Constata-se aqui a aplicação da teoria dos geossistemas para a compreensão dos processos envolvidos na formação das unidades de estudo.

Diante do sistema apresentado, verifica-se que no desenvolvimento de cavernas em rochas silicosas é perceptível a presença da dissolução das rochas, o que torna impossível um evento unicamente associado à ação mecânica (intemperismo físico e erosão). Essa premissa reforça uma definição focada no termo carste vinculado a outras litologias que não sejam apenas de rochas carbonáticas.

Tem-se, em rochas silicosas notadamente, condições que permitem o aparecimento de sistemas cársticos, produzindo um conjunto de formas, cuja origem teve forte contribuição do intemperismo químico. A distribuição das formas na paisagem permite, portanto, descrever o funcionamento do sistema, desde seus estágios de ingresso até a restituição das águas, da mesma forma que ambientes carbonáticos. (HARDT, 2011, p.155) 
Dessa maneira, o arenito fica mais poroso, permitindo a passagem de fluxo aquoso e deixando os grãos soltos. Nesse momento o ambiente subterrâneo fica susceptível à ampliação de condutos, galerias e salões, que se desenvolvem por meio de feições erosivas designadas como pipings (Figura 07).

Figura 7 - Modelo esquemático de evolução das feições erosivas piping, por arenitização Fonte: Adaptado de Fabri e Augustin (2013)

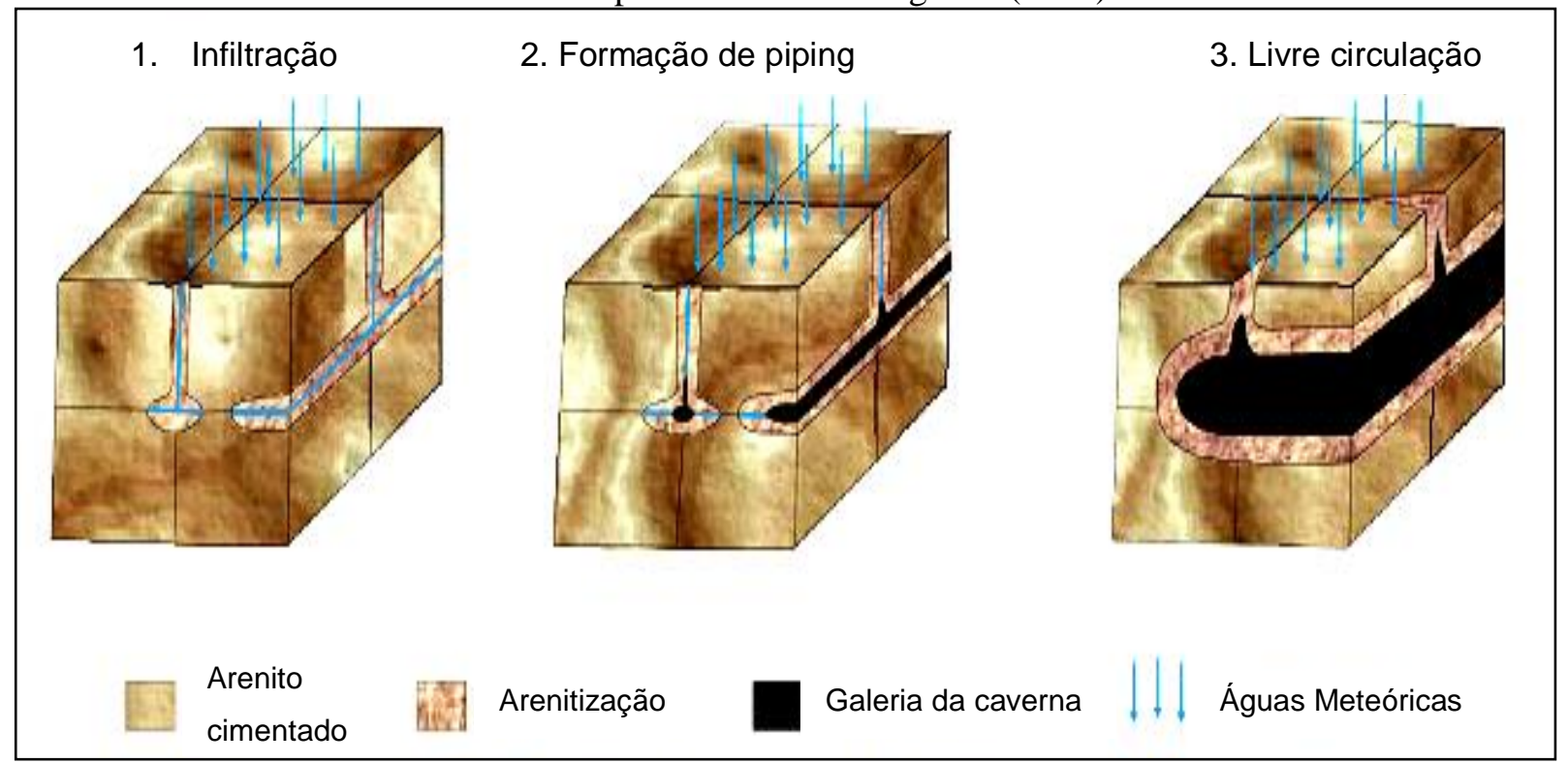

Como a própria denominação afirma, as cavidades naturais subterrâneas desenvolvem-se a partir da erosão hídrica subterrânea, realizado pelo trabalho de escavamento dessas subsuperfícies, ao passo que as entradas das cavidades são expostas pelo recuo erosivo das escarpas da cuesta. Acrescenta-se ao fato de que as rochas areníticas da Formação Maecuru estão posicionadas imediatamente adjacente às rochas do embasamento cristalino, condicionando "a presença de uma zona de alto fluxo hidráulico, potencializando a ação geoquímica e erosiva das águas meteóricas para a formação das cavernas" (PINHEIRO et al., 2015, p.15).

Em um estudo sobre os processos de formação do relevo cárstico não carbonáticas em Arkansas, nos Estados Unidos, Ogden (1981) destaca algumas características que são comuns às ocorrentes nas cavernas da região de Altamira-Itaituba: piping; dissolução de sílica; colapsos e quedas bruscas de grandes blocos rochosos; e deslizamento por queda de blocos. Consideram-se, também, as semelhanças nas feições litológicas, geológicas e morfológicas em ambas regiões. 
Na região interna das cavernas (endocarste) da Província, as feições cársticas não apresentam estalactites nem estalagmites, aspectos morfológicos bastante comuns em cavernas carbonáticas. Os ornamentos mais comuns presentes nas cavernas areníticas têm esculturação ruiniforme, tais como coralóides (corais de sílica, ou coralloids), pipocas de sílica, caixas de ovos, scallops (Figura 08), cascas de ovo, tetos anastomosados (Figura 09) e cúpulas de dissolução (Figura 10) ou chaminés de equilíbrio (SPOLADORE; COTTAS, 2007; ELETROBRÁS, 2009; HARDT, 2011). As paredes internas das cavernas estão revestidas por cimento silicoso, ferruginoso e/ou fosfático, que formam os espeleotemas. Os coralóides e as pipocas de sílica são provenientes da dissolução da rocha arenítica (arenitização), no qual Spoladore e Cottas (2007) explicam sua ação pelo gotejamento e escorrimento de soluções aquosas saturadas nestes compostos, movimentando-se mediante a ação da gravidade.

Figura 8 - Aspecto de scallops no teto da caverna do Limoeiro, Medicilância (PA)

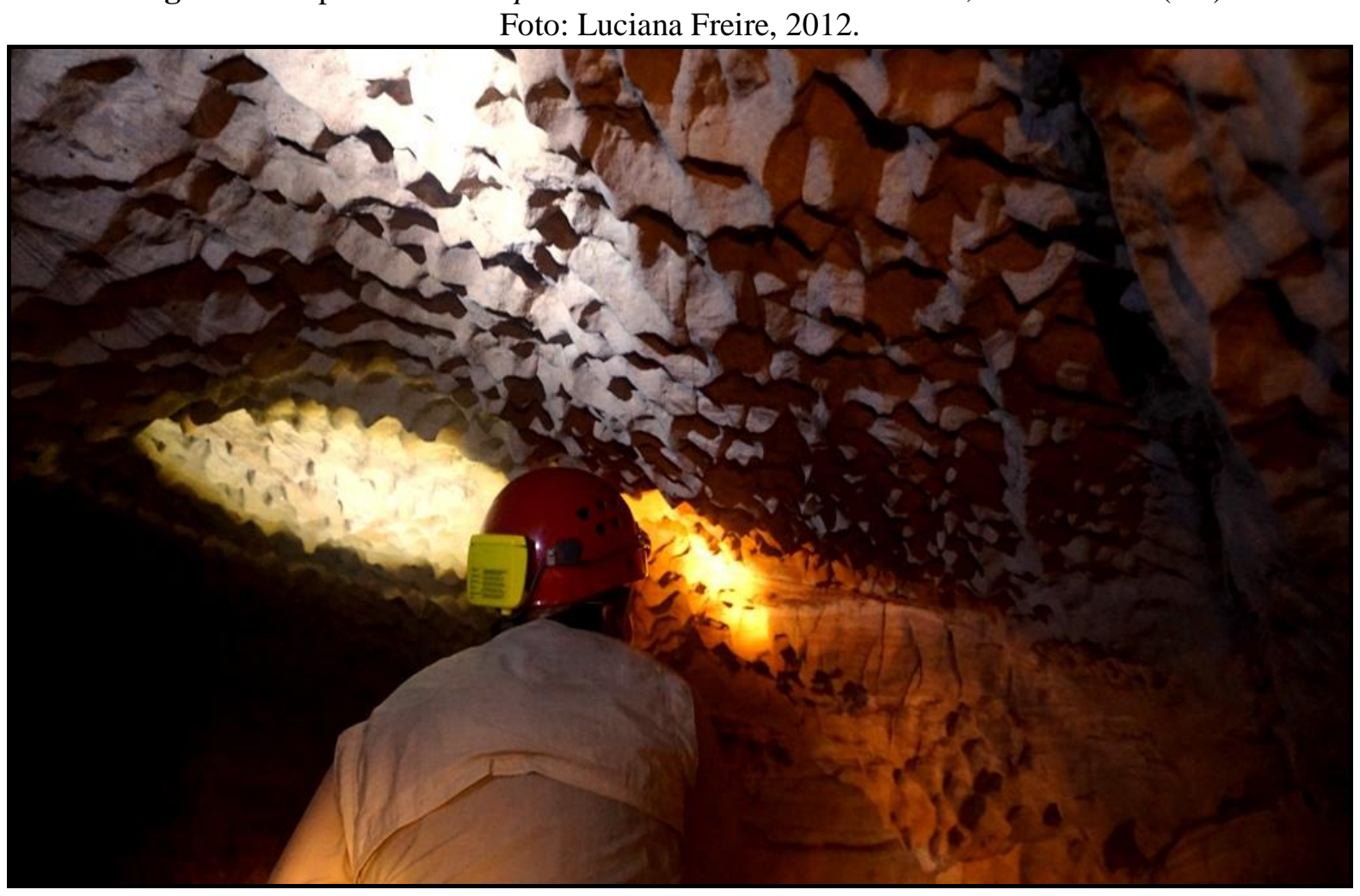


Figura 9 - Teto anastomosado na Caverna Pedra da Cachoeira, Altamira (PA). Foto: Luciana Freire, 2015.

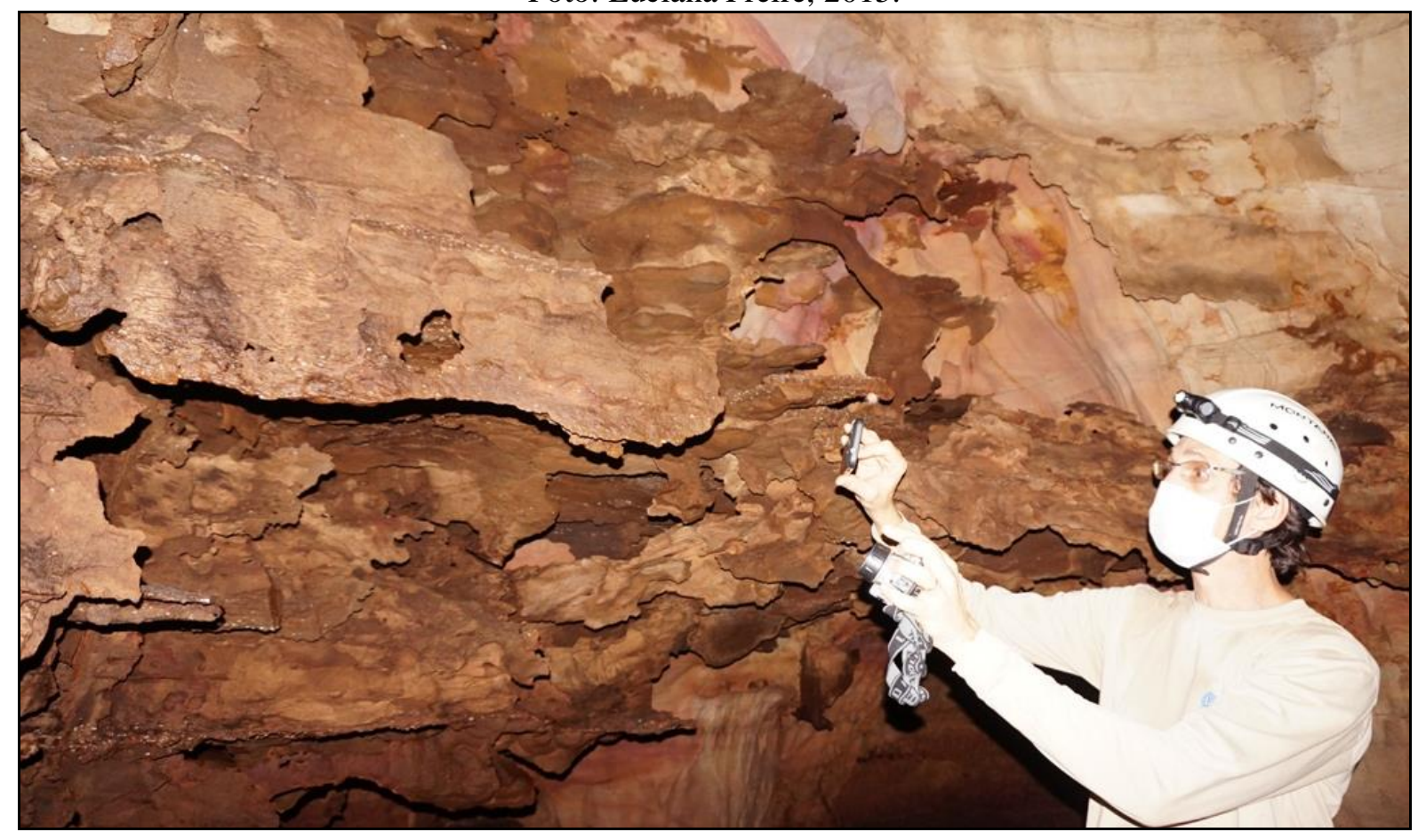

Figura 10 - (A) presença de cúpulas de dissolução, com presença de morcegos sobrevoando a área. (B) Detalhe do teto com noção de escala da área observada. Caverna do Limoeiro, Medicilânia (PA). Fotos: Luciana Freire e Edson da Silva, 2015.

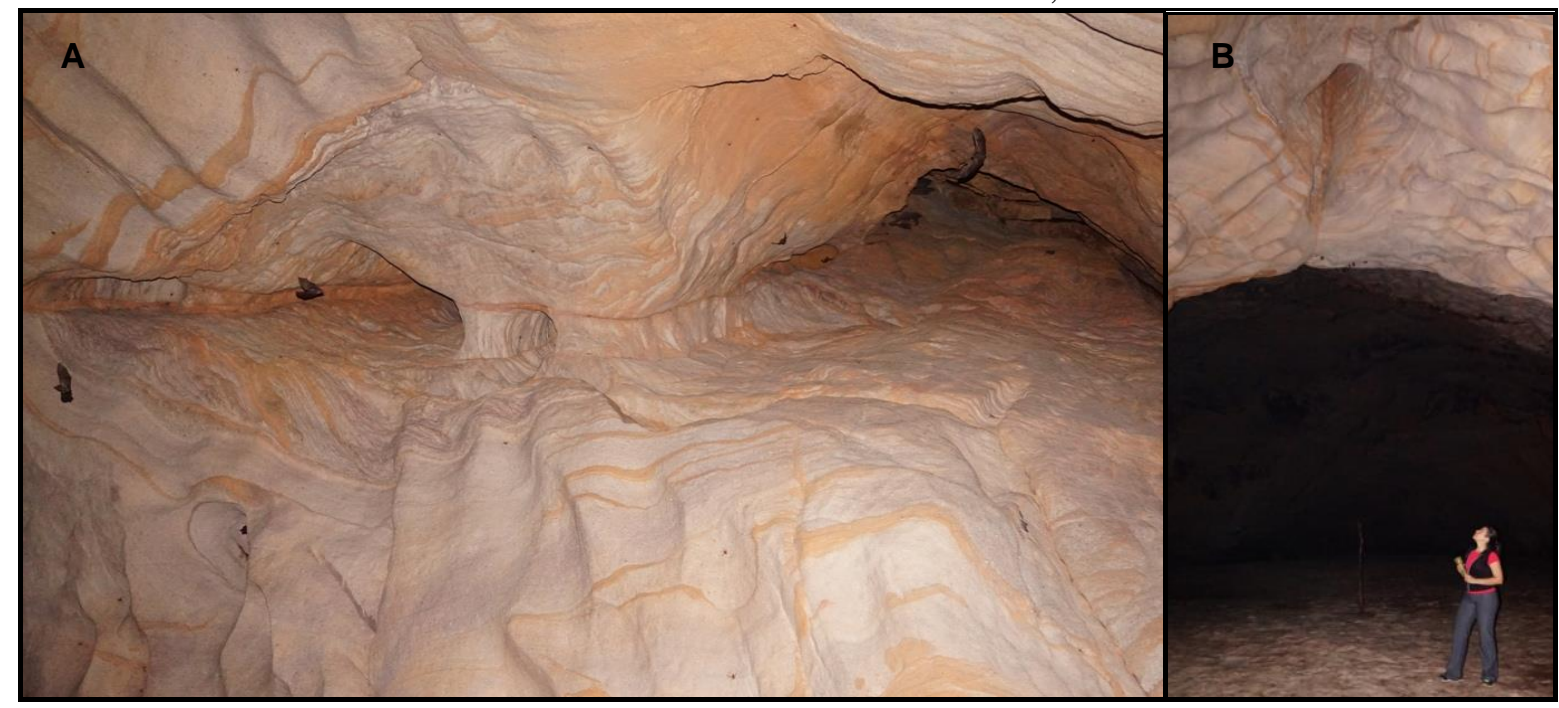

\section{CONSIDERAÇÕES FINAIS}

As características geoespeleológicas da Província Espeleológica Altamira- Itautuba (PA) apresentam o desenvolvimento de carste em arenitos, em que os processos de formação das cavernas estão associados ao desgaste mecânico das rochas, iniciados pela arenitização. A sequência evolutiva do revelo cárstico no arenito inicia-se pelo gradiente hidráulico e as zonas 
de percolação de água (planos de falhas/fraturas, acamamento, estratificação planoparalela/cruzada, etc.), onde se desenvolvem fenômenos de dissolução por silícia. $\mathrm{Na}$ sequência, ocorre a perda de coesão do material arenoso, levando a remoção de partículas mais finas, processo denominado pipping.

A abertura de condutos e salões subterrâneos segue com colapsos e deslizamentos por desabamento de blocos. Esse levantamento revela a importância que a ciência geomorfológica deve direcionar para esta abordagem ao estudo do carste, cabendo assim um maior reconhecimento. Acredita-se que surjam esforços em novos estudos voltados para pesquisas espeleológicas em universidades, centros de pesquisas e grupos de estudo espeleológico.

\section{AGRADECIMENTOS}

Ao Professor Dr. Roberto Vizeu Lima Pinheiro (FAGEO-IG/UFPA), pelo auxílio incondicional nas pesquisas espeleológicas da Amazônia brasileira. À FAPESPA (Fundação Amazônia de Amparo a Estudos e Pesquisas), pela viabilização financeira da pesquisa (Edital 005/2014). À CAPES (Coordenação de Aperfeiçoamento de Pessoal de Nível Superior), pela bolsa de doutorado. Às Universidades Federal do Pará (UFPA) e do Ceará (UFC), pela estrutura e apoio logístico.

\section{REFERÊNCIAS}

AULER, A. S. Relevância de Cavidades Naturais Subterrâneas - Contextualização, Impactos Ambientais e Aspectos Turísticos. Relatório 01. Projeto BRA/01/039. Ministério de Minas e Energia. Secretaria Executiva. 166pp; Brasília, DF. 2006. ANDREYCHOUK, V.; DUBLYANSKY, Y; EZHOV, Y; LYSENIN, G. Karst in the Earth's Crust: its distribution and principal types. Poland: University of Silesia/ Ukrainian Academy of Sciences/ Tavrichesky National University-Ukrainian Institute of Speleology and Karstology, 2009.

BERTRAND, G. Paisagem e Geografia Física Global - esboço metodológico. Caderno de

Ciências da Terra. São Paulo, SP: Instituto de Geografia - USP, 1972 BIGARELlA, J. J.; BECKER, R. D.; SANTOS, G. F. Estrutura e Origem das Paisagens Tropicais e Subtropicais: fundamentos geológicos-geográficos, alteração química e física das rochas e relevo cárstico e dômico. Florianópolis, Editora da UFSC, 1994. 425p CADASTRO NACIONAL DE CAVERNAS / SOCIEDADE BRASILEIRA DE ESPELEOLOGIA - CNC/SBE. CNC - Cadastro Nacional de Cavernas do Brasil. 
Disponível em: $\quad \leq$ http://cnc.cavernas.org.br $>$ Acesso em 29 fev. 2016. CENTRO NACIONAL DE PESQUISA E CONSERVAÇÃO DE CAVERNAS (CECAV/ICMBIO). II Curso de Espeleologia e Licenciamento Ambiental. Brasília: CECAV/ICMBio, 2008.

CRescencio, G. A Proto-História da Espeleologia na Amazônia. Anais do $31^{\circ}$ Congresso Brasileiro de Espeleologia. Ponta Grossa: SBE, 2011. p.299-305. ELETRONORTE. Aproveitamento Hidrelétrico Belo Monte: Estudo de Impacto Ambiental. Brasília: Centrais Elétricas do Norte do Brasil (ELETRONORTE), 2009. FABRI, Fabiana Pena; AUGUSTIN, Cristina Helena Ribeiro Rocha. Fatores e processos envolvidos no desenvolvimento de formas cársticas em rochas siliciclásticas em Minas Gerais, Brasil. Revista Geografias. Vol. 9, n 1, UFMG: Belo Horizonte, 2013. p. 86-96. FREIRE, L. M.; VERÍSSIMO, C. U. V.; SILVA, E. V; PINHEIRO, R. V. L.; LIMA, J. S. Consideração sobre o carste não-carbonático da Província Espeleológica AltamiraItaituba (PA), Brasil. In: GORAYEB, P. S. S, LIMA, A. M. M. Contribuições à Geoecologia da Amazônia. Vol.9, Belém: SBG-Núcleo Norte, 2015. p. 67-80. GLAZEK, J. Karst Related Phenomena - The Problem of Proper Nomenclature. 9th International Symposium on Pseudokarst (Abstracts). Institute of Nature Conservation. 2006. p. 47-48.

GUARESCHI, V. D.; NUMMER, A. V. Relevos cársticos em rochas não calcárias: uma revisão de conceitos. In: FIGUEIREDO, L. C.; FIGUEIRÓ, A. S. (Org.). Geografia do Rio Grande do Sul: Temas em debate. Santa Maria: UFSM, 2010. p. 183-194. HARDT, R. Da carstificação em arenitos. Aproximação com o suporte de geotecnologias. À propos de la karsification dans les grès. Traitement par les technologies SIG. (Tese de Doutorado) Instituto de Geociências e Ciências Exatas. Universidade Estadual Paulista Julio de Mesquita Filho, 2011.

HARDT, R.; RODET, J. O primocarte. Um novo paradigma de carstificação e sua importância no carste não carbonático. Anais do $9^{\circ}$ Simpósio Nacional de Geomorfologia. Rio de Janeiro: UFRJ, 2013.

HARDT, R.; RODET, J.; PINTO, S. dos A.F.; WILLEMS, L. Exemplos Brasileiros de Carste em Arenito: Chapada dos Guimarães (MT) e Serra de Itaqueri (SP). EspeleoTema, v.20, n.1/2, 2009. p.07-23.

Carste em Arenito: considerações gerais. Anais do XXVII Congresso Brasileiro de $\begin{array}{llll}\text { Espeleologia. } & \text { Januária: } & \text { SBE, } & \text { 2003, }\end{array}$ 
HARDT, R; PINTO, S. A. F. Carste em Litologias não carbonáticas. Revista Brasileira de Geomorfologia, Rio de Janeiro, 2009. v.10, n.2, p.99-105. KARMANN, I. Caracterização Geral e Aspectos Genéticos da Gruta Arenítica "Refúgio do Maroaga", Am-02. Espeleo-Tema, 15, SBE: São Paulo, 1986. p.9-18. KOHLER, H. C. Geomorfologia Cárstica. In: GUERRA, A. T. G.; e CUNHA, S. B. Geomorfologia, uma atualização de bases e conceitos. Rio de Janeiro: Bertrand Brasil, 2007.

MASSUQUETO, L.L.; GUIMARÃES, G.B.; PONTES, H.S. Geossítio do Sumidouro do Rio Quebra-Perna (Ponta Grossa, PR, Brasil): relevante exemplo de sistema cárstico nos arenitos da Formação Furnas. Espeleo-Tema: Campinas, SBE, v.22, n.1, 2011. MORAIS, F.; ROCHA, S. Cavernas em arenito no planalto residual do Tocantins. Revista Espeleo-Tema. Campinas, SP: SBE: 2011, p. 127-137. MORAIS, F.; SOUZA, L. B. Cavernas em arenito na porção Setentrional da Serra do Lajeado Estado do Tocantins, Brasil. Revista de Biologia e Ciências da Terra. v.9 (2), p. 113 , 2009.

OGDEN, A.E. Pseudo karst caves of Arkansas. Proc. of the Eughth International Cong. Spel., VOL. I \& II, 1981. p.766-767.

PINHEIRO, R.V.L.; MAURITY, C.W.; PEREIRA, E. Cavernas em arenito da Província Espeleológica Altamira Itaituba: dados espeleogenéticos com base no exemplo da Gruta das Mãos (PA), Amazônia, Brasil. Espeleo-Tema. v.26, n.1, Campinas: SBE, 2015. p.5-18. PINHEIRO, R.V.L.; MAURITY, C.W. As cavernas em rochas intempéricas da Serra dos Carajás Brasil. Congresso de Espeleologia da América Latina e do Caribe. 1, Belo Horizonte. Anais. Belo Horizonte: SBE, p.179-186, 1988. PONTES, H. S.; MELO, M. S. Caverna da Chaminé, Ponta Grossa, PR, Brasil: Potencial espeleológico, recursos hídricos subterrâneos e riscos geoambientais. Espeleo-Tema. v.22, n.1. 2011.

PROJETO RADAMBRASIL. Levantamento de Recursos Naturais Volume 05: Folha SA22 Belém; geologia, geomorfologia, solos, vegetação e uso potencial da terra. Ministério das Minas e Energia - MME/DNPM, Rio de Janeiro, 1974. SAllum Filho, W.; KARMANN, I. Dolinas em Arenitos da Bacia do Paraná: evidências de carste subjacente em Jardim (MS) e Ponta Grossa (PR). Revista Brasileira de Geociências. 37(3): 551-564. 2007.

SCHNEIDER, et al. Amazônia Sustentável: limitantes e oportunidades para o 
desenvolvimento rural. Brasília: Banco Mundial; Belém: Imazon, 2000. SIMMERT, H. What is Pseudokarst? In: Proceedings of the 11th International Symposium on Pseudokarst. Saupsdorf - Saxon Switzerland, Germany: UIS, 2010. p.97-100. SOTCHAVA, V. B. Por uma teoria de classificação de geossistemas da vida terrestre. São Paulo: Instituto de Geografia USP, 1978. . O estudo de geossistemas. São Paulo: Instituto de Geografia USP, 1977. SPOLADORE, A. A Geologia e a Geoespeleologia como instrumentos de planejamento para o desenvolvimento do turismo - o caso de São Jerônimo da Serra / PR. Tese de Doutorado. UNESP / Campus de Rio Claro, SP. 2006. SPOLADORE, A.; COTTAS, L. R. Ornamentos de cavernas areníticas. Anais do XXIX Congresso Brasileiro de Espeleologia. Ouro Preto - MG. Sociedade Brasileira de Espeleologia, 2007.

SUGUIO, K. Geologia do Quaternário e Mudanças Ambientais. São Paulo, Oficina de Textos, 2010.

TRAVASSOS, L.E.P. Carstologia e a pesquisa científica. Revista Territorium Terram, v. 2, n. 4, p.2-14, 2014.

URBAN, J., OTESKA-BUDZYN, J. Geodiversity of pseudokarst caves as the reason for their scientific importance and motive of protection. Geologica Balcanica, 28, 3-4, Sofia, 1998. p. 163-166.

VASQUES, M. L.; ROSA-COSTA, L. T. (Orgs.). Geologia e Recursos Minerais do Estado do Pará: Sistema de Informações Geográficas - SIG: texto explicativo dos mapas Geológico e Tectônico e de Recursos Minerais do Estado do Pará. Organizadores, Escala 1:1.000.000. Belém: CPRM, 2008.

VERISSIMO, C. U. V.; SPOLADORE, A. Gruta do Fazendão (SP-170): considerações geológicas e genéticas. Espeleo-Tema, SBE, v. $17, \quad$ p. $7-17,1994$. WERNICK, E.; PASTORE, E. R. B.; PIRES NETO, A. Cavernas em arenito. Notícia Geomorfológica, 13(26): 55-67, 1976.

WHITE, W. B. Geomorphology and Hydrology of Karst Terrains. New York: Oxford University Press, 1988.

YOUNGER, P. L.; STUNELL, J. M. Karst and pseudokarst : An artificial distinction ? In : Brown, A.G. (ed.). Geomorphology and Groundwater. John Wiley \& Sons, 1995. p. 121-142. 